ISSN 1518-3483

Licenciado sob uma Licença Creative Commons

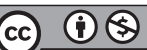

\title{
Da prática pedagógica do formador do alfabetizador, perspectivas para a didática
}

\section{Didactics perspectives from the pedagogical practice of literacy teacher developers}

\author{
Maria Sílvia Bacila Winkeler ${ }^{[a]}$, Pura Lúcia Oliver Martins ${ }^{[b]}$ \\ [a] Professora do Curso de Pedagogia da Pontifícia Universidade Católica do Paraná (PUCPR), Curitiba, \\ PR - Brasil, e-mail: silvia.bacila@gmail.com \\ [b] Professora do Programa de Pós-Graduação em Educação e do Curso de Pedagogia da Pontifícia \\ Universidade Católica do Paraná (PUCPR), Curitiba, PR - Brasil, e-mail: pura.oliver@pucpr.br
}

\section{Resumo}

Este artigo apresenta perspectivas para a Didática do formador do alfabetizador a partir da sistematização de práticas produzidas por formadores de professores alfabetizadores no ensino superior. Parte do pressuposto de que a didática sistematizada na literatura da área, expressa uma prática pedagógica decorrente de determinado tipo de relação social no interior do modo de produção que a sustenta. Toma como eixo epistemológico a Didática prática defendida por Martins (2009) e os conhecimentos dela decorrentes, o que implica analisar essa prática numa relação de causalidade complexa. Desse ponto de 
vista, as perspectivas para a didática, apresentadas neste artigo, não são prescrições, mas indicadores de caminhos possíveis para a organização e realização da prática pedagógica na formação do professor alfabetizador. Os resultados contribuem com a prática pedagógica desse formador e vão ao encontro das perspectivas da formação do professor leitor em diferentes situações, tendo como orientação a leitura, a interpretação, a escrita e a criação de significados, gerando, por meio dessa didática, um letramento específico na formação do alfabetizador: o letramento alfabetizador.

Palavras-chave: Didática. Prática pedagógica. Alfabetização. Letramento. Formação de professores.

\section{Abstract}

This article presents didactic perspectives for literacy teacher developers by systematizing the practices produced by literacy educator developers in higher education. It starts from the assumption that the systematic teaching of the literature in the area expresses a pedagogical practice arising from a particular type of social relationship within the mode of production that sustains it. It has as its epistemological axis the 'Didactics practice' advocated by Martins (2009) and the knowledge arising from it, which implies analyzing this practice in a complex causal relationship. From this point of view, the prospects for didactics presented in this article are not requirements, but indicators of possible paths for the organization and implementation of a pedagogical practice in the development of literacy educators. The results contribute to the pedagogical practice of literacy educators and match the development perspective of reader teachers in different situations, having reading, interpretation, writing and creation of meanings as guidelines, generating - through this teaching practice - $a$ specific approach for developing literacy educators: alphabetizing literacy.

Keywords: Didactics. Pedagogical practice. Literacy. Alphabetizing. Teacher Development.

\section{Introdução}

Este artigo discute a didática do formador do alfabetizador a partir da investigação da sua prática pedagógica nos cursos presenciais de 
Pedagogia de Curitiba. Partimos do pressuposto que a didática sistematizada na literatura da área expressa uma prática pedagógica decorrente de determinado tipo de relação social no interior do modo de produção que a sustenta. Nessa perspectiva, a didática não se constitui guia da ação como pretendem os manuais, mas como expressão de uma prática determinada, num momento histórico determinado.

Partindo da sistematização da prática pedagógica desenvolvida pelo formador do alfabetizador, trazemos para discussão algumas perspectivas para a didática, não como prescrição, mas como indicadores de caminhos possíveis para a organização e realização da prática pedagógica na formação do professor alfabetizador.

Para tanto, esse estudo toma como eixo epistemológico a Didática prática (MARTINS, 2009) e os conhecimentos dela decorrentes. Isso implica analisar a prática pedagógica dos formadores sujeitos da pesquisa, numa relação de causalidade complexa em que "O determinado não é concebido como expressão do determinante, porque a ação deste consiste em marcar a amplitude da ação do determinado, e não sua forma de realização" (BERNARDO, 1977, p. 60). Nessa perspectiva, uma prática pedagógica forjada pelo professor "não se constitui numa causa única que provoca um efeito único previsível, mas abre um campo enorme de possíveis resultados, pressupondo novas relações professor-aluno, professor-professor, novas relações organizacionais no interior da escola, novas relações frente ao conhecimento" (MARTINS, 2009, p. 140).

Com efeito entendemos que é nas tensões da prática pedagógica refletida, a qual se presta atenção, tocada pela experiência vivida que se constitui uma didática do formador do professor alfabetizador, expressão do seu tempo. Há uma complexidade implícita quando se fala em prática pedagógica e não se pode pensá-la em uma relação de causalidade simples. São várias as questões, como o contexto social e histórico em que a prática pedagógica está inserida, o conhecimento produzido, as ideologias, os sujeitos que dela participa, as orientações e as contradições que os planos de ensino carregam no ensino superior, a experiência dos formadores e os sentidos atribuídos em distintas situações, além das práticas produzidas 
pelos formadores do professor alfabetizador no ensino superior de que decorrem perspectivas para uma didática do formador do alfabetizador que aqui se apresenta. Essas perspectivas da didática emanam da necessidade de ensinar uma área específica do conhecimento, o campo científico da alfabetização, e também incidem na ação pedagógica da alfabetização, ensinar a ensinar a ler, interpretar, escrever e criar significados.

A opção metodológica utilizada para compor este estudo de natureza qualitativa foi a modalidade estudo de caso instrumental, baseado em André (2008), Stake (2011) e Chizzotti (2006), que teve como unidade de análise a disciplina de Alfabetização nos cursos de Pedagogia presenciais de Curitiba. As estratégias de coleta de informações utilizadas constituíram-se em entrevista episódica e análise documental (FLICK, 2009). Os dados coletados foram produzidos e analisados apoiados na análise textual discursiva, segundo Moraes e Galiazzi (2011).

Tendo como entendimento o eixo epistemológico da didática prática, segundo o qual não há uma prática pedagógica que "deveria ser", sem confundi-la com um "ideal de prática", é que se chega às práticas que os sujeitos da pesquisa verbalizaram nas entrevistas a fim de buscar os sentidos que elas traduzem na formação do professor alfabetizador. Não há como abordar a prática pedagógica sem associá-la ao campo da didática, porém, com esse eixo epistemológico, será visto o que está sendo produzido, pois a prática pedagógica produz uma didática quando se compreende a teoria como expressão da prática (MARTINS, 2009).

Sob esse ponto de vista, estrutura-se a análise das práticas pedagógicas dos formadores do professor alfabetizador nesse estudo. Essas práticas não nascem de uma prescrição da didática, mas são compreendidas como uma produção dos sujeitos da pesquisa, sujeitos de uma prática social situada e datada. As evidências encontradas mostram que é possível pensar em uma didática do formador do professor alfabetizador como sistematização das práticas pedagógicas por eles produzidas no contexto do ensino superior. 


\section{Práticas produzidas na formação do alfabetizador}

As práticas pedagógicas aqui apresentadas reúnem aspectos da experiência dos formadores, de áreas do conhecimento paralelas à alfabetização, como a metodologia científica, a didática geral, das classes alfabetizadoras, das tecnologias da informação e da comunicação, assim como questões linguísticas, específicas desse conhecimento.

Uma das práticas relatada foi inventariada como memorial, memorial reflexivo e memórias, nas quais se identifica uma preocupação com a formação do alfabetizador como leitor da sua própria história, leitor de mundo, leitor das palavras e dos textos, escritor e produtor de significados. A leitura é o resultado de uma interação, trata-se de um diálogo entre autor e leitor mediado pelo texto, neste caso, mediado pelo texto de sua existência, fazendo a interlocução com os textos da área de alfabetização, com os significados que essas leituras podem imprimir no professor que lê, interpreta, significa, escreve, de forma que também ele formará leitores que interpretem, escrevam e produzam significados.

Um memorial que marcou a educação brasileira foi Travessia, escrito por Magda Soares, em 1981, por ocasião de seu concurso para professor titular da Universidade Federal de Minas Gerais. Nessa obra, Soares (1981, p. 2) explica que defendeu o gênero como uma prova do concurso, pois este obriga o professor universitário a ultrapassar o que fez, analisando, criticando e justificando para que fez e como fez, além da enumeração que está em seu curriculum vitae. Sendo assim, o memorial seria adequado para a prova do professor titular, aquele que já teria passado por todos os degraus da carreira docente, chegando ao último, como um convite a refletir sobre seu passado acadêmico. A autora nos auxilia a entender o gênero quando explica o que fez em seu texto: "[...] devo contar o que fui, o que foi, devo explicar o passado. Mas antes de explicar o passado, é preciso explicar o presente, este presente". Objetivamente, para a autora, o presente era a condição do seu concurso, o qual desencadeava a "chave para a compreensão do passado, que só pode ser avaliado a partir dos seus efeitos" (SOARES, 1981, p. 3). A leitura da realidade 
objetiva e seus efeitos é que proporciona a leitura do passado de maneira que se possa avaliar suas implicações.

A leitura provocada no memorial nos conduz à leitura da palavra mundo proposta por Freire (2005) em sua obra A importância do ato de ler, quando recomenda aos professores que a leitura de mundo antecede à leitura das palavras. Conta sobre sua infância, quando suas primeiras aprendizagens relacionadas à leitura foram sobre a casa em que vivia, as árvores que lá estavam, os significados do universo social que o compunha como sujeito histórico. Depois de aprender a ler esses mundos e significados, entrou no mundo das letras e, desses novos significados, com um repertório que lhe dava suporte para decifrar tais códigos, com propriedade, situou-se como sujeito dessa história e como alguém que, tendo domínio desses códigos, deixaria sua história como um legado. E deixou.

A entrevista de Ágata mostra como trabalha com o memorial reflexivo.

No primeiro dia de aula eu digo para elas: - Olha, a gente vai construir uma coisa durante esse primeiro bimestre que é o trabalho de vocês e que se chama "Memorial reflexivo". É um instrumento que a gente criou junto, pela experiência do trabalho. Ah! O que é Memorial reflexivo? Memorial reflexivo é um documento que o aluno entrega no dia da prova e que envolve três acervos: $O$ acervo bibliográfico de tudo que foi discutido, o acervo da aluna (aquilo que ela tem de vivência) e as discussões que são feitas em sala de aula. É um documento redigido individualmente. [...] E elas redigem, elas fazem uma redação. [...]. Aí elas entendem por que é importante ler e escrever, como é que eu faço para ler, para compreender, para interpretar, para desdobrar a minha interpretação, para escrever isso que eu estou entendendo, que espaço é este que existe entre aquilo que eu compreendo, aquilo que eu falo e aquilo que eu vou escrever... [...] Esse esforço que a gente faz (Ágata, grifos do autor).

Os critérios de Ágata esclarecem o uso do seu memorial, o qual recebe um predicado: reflexivo. No seu memorial reflexivo, os alunos seguem os passos dela: "Memorial reflexivo é um documento que o aluno entrega no dia da prova e que envolve três acervos: o acervo bibliográfico 
de tudo que foi discutido, o acervo da aluna (aquilo que ela tem de vivência) e as discussões que são feitas em sala de aula". Os acervos aos quais Ágata se refere são os textos que os alunos produzem sobre as leituras que fizeram, relacionadas às bibliografias indicadas, às vivências e às discussões em sala. Lajolo (2000) elucida que um texto é sempre produzido em um momento histórico, ou seja, é datado social e historicamente, definido por expectativas derivadas de informações e conhecimentos compartilhados pelos possíveis interlocutores.

Quando aborda que a partir das leituras, nesse memorial, "elas redigem, elas fazem uma redação”, traz à tona a concepção de Azambuja e Souza (2009), que auxiliam a compreender o estudo de texto como técnica de ensino. Estudar um texto é um ato analítico e crítico, desvendando e percebendo sua estrutura, seus recursos, descobrindo o objetivo do autor. Indicam que as estratégias de leitura são utilizadas nesta tarefa, sejam elas de análise, síntese, julgamento, seleção, predição, inferência, mas é necessário que haja a produção própria, em que os alunos exteriorizem algo que adquiriram com o estudo de texto. No caso do memorial reflexivo relatado por Ágata, essa fase do estudo de texto se refere ao seu "acervo bibliográfico" e condiz com o estudo de texto, uma vez que solicita aos alunos a produção do que compreenderam sobre suas leituras. Em nome desse acervo, vai explicando outras questões que estão implicadas:

essa é uma estratégia que eu tenho usado! É interessante como a cultura do ler e do escrever fica posta, porque no primeiro semestre que eu apliquei, que eu comecei a trabalhar assim tinha muita briga "Ah! Porque a professora pede, porque a professora quer que leia!" A primeira vez que eu pedi para ler um livro inteiro foi uma loucura!

A formação do professor leitor tem se tornado um desafio, e sua entrevista retrata essa situação ao solicitar a leitura de um livro por inteiro. Segue relatando os resultados que obtém e que foi solidificando ao longo do tempo, deixando sua marca na instituição.

Formar leitores é uma prerrogativa da alfabetização e, com isso, da prática do formador do alfabetizador. A literatura infantil é um 
universo de magia e encanto que não atinge somente crianças, mas adultos também. Povoa a imaginação com histórias, possibilitando a construção de cenas e imagens para cada leitor. A familiarização do aluno em formação com essa literatura constitui uma das práticas do formador do alfabetizador. Na prática da formação do alfabetizador, ao invés de ler a própria história, na literatura infantil é convidado a ler as histórias de outras pessoas e com isso suscitar o imaginário, encontrar outras ideias para solucionar questões, conforme os personagens fizeram, em uma possibilidade de descobrir um mundo de conflitos, impasses e de soluções, resolvidos ou não, pelos personagens, conforme explica Abramovich (2006). A autora destaca a relevância de contar histórias para as crianças, sendo, então, igualmente uma aprendizagem importante para o alfabetizador. Explica que é ouvindo histórias que se podem sentir emoções, tais como raiva, tristeza, irritação, bem-estar, alegria, pavor, tranquilidade, insegurança e outras mais e viver profundamente o que as narrativas propõem.

Não entrarei nos conflitos acerca da existência de uma literatura infantil, neste estudo, porém é indiscutível a materialidade da obra. A "célula mater" da literatura infantil concentra-se na ideia da oralidade, quando o homem sentiu a necessidade de contar suas histórias, não necessariamente infantis. Constitui-se como gênero no século XVII com a ascensão da família burguesa e com o novo status concedido à infância nesse cenário. Contar histórias vem como uma tradição de longa data e se tornou uma prática pedagógica do alfabetizador. Mas há que se saber contar adequadamente uma história para que se suscitem profundamente os sentimentos, conforme a literatura infantil sugere. Só sabe contar uma história aquele que lê e estabelece uma identidade com aquela história, que entra nos personagens, nas emoções e traduz para o público sua interpretação. Com isso, toca-se em algo frágil ${ }^{1}$ na formação do

${ }^{1}$ Em pesquisa orientada sobre a formação do professor alfabetizador no Programa de Bolsa de Iniciação à Docência (PIBID), "O desafio de formar alunos adolescentes em professores" (SANTOS; WINKELER, 2011), obtivemos resultados que indicam a necessidade da formação do professor alfabetizador como leitor, uma vez que a leitura não é uma prática desses alunos em formação.

Rev. Diálogo Educ., Curitiba, v. 12, n. 35, p. 143-164, jan./abr. 2012 
alfabetizador que é, antes de mobilizá-lo a contar uma história, formá-lo leitor de histórias. Andrade (2007) realizou uma pesquisa sobre a leitura na formação docente e assinala que é desejável que o professor da língua materna, neste caso o alfabetizador, seja um bom leitor, de modo que sua experiência da leitura, o conhecimento e o prazer da literatura constituam a experiência do docente e lhe permitam a realização de sua autonomia. Aconselha, ainda, que o horizonte da literatura atinja a de adultos, mas não descarta a experiência com a juvenil e a infantil.

Dois dos sujeitos da pesquisa relatam suas práticas na formação do alfabetizador envolvendo a literatura infantil e a contação de histórias. Iolita remete-se à importância de contar histórias para crianças e faz alusão a que, posteriormente à história, seus alunos promoveriam alguma atividade, como um jogo. Sua entrevista atesta a seguir:

a contação de história eu fiz em um período falando da importância de se contar a história para as crianças. O restante elas fariam como trabalho, poderia ser um jogo ou uma coisa mais difícil. [...] Fizeram material de sucata para contar a história e conseguiram colocar em prática quando elas foram fazer estágio (Iolita).

Fica implícito em seu relato que, antes de os alunos contarem as histórias em seus estágios, realizaram primeiramente a contação em sala de aula para os colegas, quando narra "E ele era um mágico, colocou aquele chapéu de mágico, uma capa e contou histórias para nós”. Depois explica: "No dia da intervenção dele, ele se vestiu de mágico...”. Entendese que os alunos primeiro fazem a atividade em sala e depois nos estágios. Isso ocorre também com Jade quando relata a atividade que realizou sobre contação de histórias utilizando um avental com fantoches de velcro: "Então, pelo menos o fato de você demonstrar na sala de aula, de você fazer de conta que tem criança ali mesmo".

Um aspecto que está tributado a essa atividade da literatura infantil é o planejamento de uma atividade pedagógica relacionada à alfabetização, como extensão da contação de histórias. Abramovich (2006, p. 148) considera importante que, após a leitura de um livro, os 
alunos façam apreciações sobre as histórias, se gostaram ou não, e que argumentem suas opiniões, pois considera a discussão um momento de aprendizagem até para se perceber que não há unanimidade em gosto por determinados livros. Destaca que o cuidado com o encaminhamento dado às atividades, ao controle de leitura, e assevera, "[...] se ler for lição de casa, a gente bem sabe no que dá...”. Em contrapartida, o uso do texto da literatura infantil como pretexto para alfabetizar é um encaminhamento frequente nas classes de alfabetização, e aqui não discutirei a integridade da literatura infantil quando utilizada nessa situação, mas me posicionarei reconhecendo que há situações em que a literatura infantil é usada como deleite e outras em que é promotora de excelentes oportunidades para a alfabetização.

Pode-se dizer que a literatura infantil é uma chave para a alfabetização e, por meio dela, vão sendo produzidas práticas que possibilitam criar condições para o letramento literário, considerando a leitura uma troca de sentidos entre o escritor e o leitor, como também com a sociedade, com a história, com o tempo e o espaço. A presença da literatura infantil como texto que conduz a um tipo de letramento, o literário, e, conforme defende Cosson (2009, p. 29), é uma prática social, e como tal, responsabilidade da escola. Explica: "ninguém nasce sabendo ler literatura”, por isso há necessidade de práticas pedagógicas que conduzam à análise literária, permitindo que o leitor compreenda a magia peculiar ao gênero. Sugere à prática pedagógica criar condições para que o encontro do aluno com a literatura seja uma busca plena de sentido para o texto literário, para o próprio aluno e para a sociedade em que estão inseridos.

Formar professores que leiam as produções infantis, identifiquem os progressos e provoquem possibilidades de avanço para as crianças vem se tornando um desafio aos formadores desde que as abordagens psicológicas da leitura e da escrita passaram a figurar no cenário da alfabetização como concepções que fundamentam a prática do alfabetizador. Zaccur (2003, p. 106) questiona a formação do professor alfabetizador a partir de modelos e alega que, geralmente, os cursos de formação de professores enfatizam o planejamento e a avaliação, não concedendo lugar 
para a reflexão sobre o "fazer pedagógico, ou sobre a análise das produções dos alunos, buscando, no avesso dos enunciados, informações sobre os sujeitos da enunciação".

Ao contrário das críticas da autora, as entrevistas relatam práticas pedagógicas preocupadas em formar o professor alfabetizador crítico, reflexivo, com a possibilidade de realizar a leitura, a interpretação e a significação das produções dos alunos e, por meio dessa compreensão, intervir para que seus alunos se desenvolvam. Tal prática pedagógica vai ao encontro da concepção de que a alfabetização é um processo que exige reflexão crítica e seus sentidos são traduzidos pelos atores que dialogam nessa ação.

Mostram, nas entrevistas, o valor de trabalhar com diferentes pontos de vista sobre a alfabetização. Entender as hipóteses sobre a leitura e a escrita de cada criança é um desafio constante, diário e do enfrentamento do professor alfabetizador. Trabalhar com argumentos e situações que mobilizem a criança a pensar sobre sua escrita e formar o professor a pensar sobre a escrita e as hipóteses que ela pode desenvolver caracteriza-se como uma atividade diagnóstica que o formador realiza com o aluno em formação. Rompem com um paradigma no qual se trabalhavam noções de igualdade de todas as crianças, etapas idênticas para todos os aprendizes ao mesmo tempo. Mostram outro ponto de partida de análise em suas práticas: a produção infantil. É dela que o alfabetizador terá que se apropriar, terá que conhecê-la e criar intimidade com ela. É uma prática pedagógica reflexiva, contextualizada, socialmente determinada, politicamente comprometida com as diferenças de cada pessoa. A entrevista de Ametista advoga em relação à análise do material produzido pela criança:

no primeiro dia de aula eu mostro um texto produzido por uma criança real, de idade de alfabetização para os alunos e a cada referencial teórico que vamos estudando eu volto neste tex to e vamos identificando o que pode ser compreendido, e que outras bases ainda são necessárias para que eles possam auxiliar esta criança se eles estivessem com ela numa sala de aula (Ametista).

Ametista utiliza a produção infantil como um elo para as leituras dos referenciais teóricos com que trabalha. Movimenta a reflexão 
por meio do conteúdo da criança: "que outras bases ainda são necessárias para que eles possam auxiliar esta criança se eles estivessem com ela numa sala de aula". Muito mais do que compreender as etapas das produções infantis por meio das abordagens psicológicas que sustentam teoricamente essa prática pedagógica, está implícito na ação do formador do professor alfabetizador um ato político, um compromisso social, uma opção por concepções da alfabetização que sustentam a prática alfabetizadora a partir da compreensão da aprendizagem do aluno e põe o professor como mediador no processo de aquisição da leitura e da escrita. Mudam a lógica do adultocentrismo tão criticada por Ferreiro e Teberosky (1999) na formação do alfabetizador, parametrizando a produção da criança como eixo de análise, de reflexão, de construção de argumentações e de encaminhamentos.

Apesar de a educação mediada por tecnologias vir surgindo gradativamente como prática pedagógica há várias décadas, é ainda uma abordagem inovadora ao trabalho docente, constituindo um desafio, segundo Santos (2010), para formadores de formadores, para os professores em sala de aula e para os responsáveis por políticas públicas. O conceito de tecnologias é variável e contextual, explica Kenski (2010). Sua definição está relacionada com a história do homem em produzir técnicas úteis para fazer coisas práticas. Na era moderna, os artefatos tecnológicos constituem uma parte importante do cotidiano de nossas vidas. As tradições tecnológicas são determinadas culturalmente e determinam a cultura em que estão inseridas. Somos muito diferentes de nossos antepassados e já nos acostumamos a utilizar determinados confortos, como luz elétrica, água encanada, fogão, telefone e nem podemos imaginar o nosso cotidiano sem esses suportes.

Nas escolas e nas universidades, a determinação cultural das tradições tecnológicas também é evidente. Santos (2010) nos auxilia a compreender as tecnologias na educação em uma vertente chamada "educomunicação", a qual congrega educação à distância, uso de software educativo, a internet como instrumento de aprendizagem, a TV e o vídeo educativo, entre outras que promovam a educação mediada pela tecnologia. 
Ao falarmos em novas tecnologias, Kenski (2010, p. 18) explica que, atualmente, fazemos referência aos processos e produtos relacionados com conhecimentos provenientes da eletrônica, da microeletrônica e das telecomunicações, as quais se caracterizam por serem evolutivas, ou seja, em permanente transformação. As mais novas tecnologias situam-se no contexto neoliberal em dois universos distintos para "os que têm senha de acesso para ingresso nessa nova realidade", ou os excluídos, os subdesenvolvidos. Lyotard (1988, 1993 apud KENSKI, 2010) explica que a única chance que o homem tem para acompanhar o movimento do mundo é buscar se adaptar à complexidade que os avanços tecnológicos impõem a todos, sem distinção. Atualmente, a tecnologia e a mídia estão configurando diferentes formas dos indivíduos lidarem com o tempo e o espaço, tornando efêmero e volátil o que se quer, o que se pensa, o que se faz, aferem Barbosa e Carvalho (2009).

Se temos certeza de que a prática pedagógica é situada e datada, diria que é, também, nesse contexto da cibercultura, online. Silva (2009, p. 75) explica que o computador online ocupa posição central na constituição da sociedade e vem englobando todos os meios de informação e comunicação anteriores, tornando-se o centro "processador da informação e da comunicação". É inegável o uso dos computadores pelos professores e a forma como as práticas pedagógicas vêm se adaptando aos suportes tecnológicos, especificamente aos que mantêm o professor conectado, ou seja, online. $\mathrm{O}$ autor alerta ainda que, se a função da educação é formar cidadãos, os professores necessitarão cuidar da cidadania no ciberespaço.

Concordo com o autor, pois, se a escola se preocupa com a formação do sujeito nascido na era digital e suas relações se ampliaram a uma sociedade de cultura digital, as responsabilidades por essa educação não pertencem unicamente à escola. Estaríamos retrocedendo historicamente, agora com o requinte da sociedade digital, a delegar a educação a um único agente social; a responsabilidade por algo que cabe a outras agências, como à família, à sociedade. Em contrapartida, é absoluta a necessidade de o professor também assumir seu papel de agente educativo nesse cenário e num lugar, quem sabe estranho para muitos docentes, 
com uma língua que não é materna, exigindo a aprendizagem de um segundo idioma, demandando vencer alguns estranhamentos que a cibercultura tributa à prática pedagógica. Palfrey e Gasser (2011) complementam a reflexão, afirmando que, nessa perspectiva, os professores têm uma enorme responsabilidade no trabalho com a qualidade das informações, no que tange à habilidade de aprender a avaliar criticamente a qualidade das informações online.

A entrevista de Safira ilustra o contexto:

ultimamente, nós estávamos trabalhando até com aqueles jogos do Orkut, minifazenda, colheita feliz. Num primeiro momento elas estranharam, porque isso parece fora do contexto. Mas isso é que as crianças estão jogando, eles estão nesse universo! Se eu quero que eles construam, o professor também tem que saber, o acadêmico que será docente também tem que saber usar na internet esses programinhas. Como é que eu utilizo isso não apenas com esse olhar de passa tempo, mas construir conhecimento a partir dele (Safira).

É possível observar na entrevista de Safira duas preocupações: com a atividade que os jogos na internet poderiam gerar como conhecimento na alfabetização e com a alfabetização digital. Mostra-se como uma formadora que explora o ciberespaço procurando encontrar alternativas para fazer do uso como lazer dessas ferramentas, uma forma de aprendizagem. E adverte: "Ou nós desconstruímos essa nossa prática que já está ficando ultrapassada e reconstruímos em novas bases, ou não vamos mais conseguir preparar o nosso aluno para esse futuro que já vai estar distanciado". Faz um convite ao formador a rever as práticas com vistas a agregar as tecnologias, tendo esta nova geração inserida na cibercultura como o aluno em potencial. Palfrey e Gasser (2011) auxiliam a descrever quem são os nativos digitais e explicam que são elites formadas por jovens em qualquer sociedade, os quais constituem o componente de uma cultura global de jovens unidos pela forma como se relacionam com a informação, com as novas tecnologias e uns com os outros. 


\section{Perspectivas para a didática do formador do alfabetizador}

Das práticas pedagógicas produzidas, foi possível identificar que elas se constituem em eventos de letramento no ensino superior, sendo o formador do professor alfabetizador o agente letrador. Ao assumir um papel que, além de mediar a relação do aluno em formação dos saberes acadêmicos com as classes alfabetizadoras, insere-o em práticas de leitura e escrita, realizando um "letramento alfabetizador", tendo a universidade como agência de letramento. $O$ texto assume o seu papel central na formação do professor alfabetizador, seja o texto de sua vida, o texto científico, o texto da criança, o texto literário ou o texto com suporte nas tecnologias, as unidades estruturadas. Nessa perspectiva, torna-se possível, ao aluno em formação, vivenciar, por meio dessa didática, uma proposta em que possa atribuir significados às práticas sociais de leitura e escrita, permitindo ao futuro alfabetizador atender à demanda das classes alfabetizadoras no que se refere à alfabetização e ao letramento.

A didática do formador do professor alfabetizador implica um letramento alfabetizador no qual, a universidade/instituição de ensino superior constitui-se em uma agência de letramento, ou seja, um espaço para as práticas sociais de leitura e escrita na formação do professor alfabetizador, as quais se compõem por uma didática própria. A didática do formador do alfabetizador propõe situações de leitura, escrita e planejamento, constituindo-se em eventos de letramento, nas quais o formador, além de mediar a formação do alfabetizador entre a universidade e as classes alfabetizadoras, constitui-se como um agente letrador, formando o leitor. Nas práticas de leitura e escrita sobre a alfabetização está letrando o aluno em formação, sendo formador e alunos protagonistas do letramento alfabetizador.

As práticas pedagógicas produzidas pelos sujeitos carregam algumas perspectivas orientadoras para a formação do professor alfabetizador. Por meio da complexidade de conhecimentos, procedimentos, circunstâncias, pesquisas, as experiências que se traduzem nas práticas dos formadores do professor alfabetizador no ensino superior é possível 
identificar a teoria que essas práticas expressam manifestando indicadores para uma didática específica do formador do professor alfabetizador. São práticas pedagógicas que não têm a prerrogativa de se tornarem prescritivas, mas exprimem um pensamento social e histórico relacionado à formação do alfabetizador no ensino superior. Reúnem, criativamente, elementos da experiência, da metodologia científica, da didática geral, da prática alfabetizadora de classes infantis, de pesquisas, de concepções histórica e socialmente determinadas em relação complexa, apontando os seguintes indicadores para uma didática da formação do alfabetizador. Assim, os estudos revelam perspectivas para a prática do formador que vão em direção de:

a) Formar o professor alfabetizador leitor de sua própria história e,
por meio dessa leitura, realizar as leituras da alfabetização

Ler e escrever o texto da sua história, da sua experiência e fazer a relação com as teorias que estão sendo estudadas é uma das prerrogativas dessa didática do formador que foi expressa por meio dos memoriais. Primeiro, buscar o significado da história de cada aluno enquanto sujeito, identificar-se com a profissão professor, relacionar sua história de vida com as teorias abordadas e garantir um evento de letramento no qual a intertextualidade está presente. Essa prática pedagógica legitima o aluno em formação como sujeito histórico, que reflete, toca em situações que tiveram significado em sua vida e ganham sentido relacionado ao tema que está estudando. Ler, interpretar, escrever e criar significados não é uma tarefa simples, e a cada etapa de nossas vidas em que somos impelidos a tal ocupação, é sempre uma nova jornada, pois o tempo determina a marcha da experiência, ou seja, a condição de outros significados que são criados.

Partir da leitura do texto da própria vida, da escrita da sua história, é dar a possibilidade ao aluno em formação de ler, interpretar, escrever e criar novos significados sobre a sua existência e sobre o texto mais próximo, mais íntimo que lhe possa ser ofertado. É desse texto que 
ele fará as relações com todos os outros que lhes serão oferecidos pela academia: os textos científicos, os textos das crianças, os textos literários, os mediados pelas tecnologias, os hipertextos e os demais. As inferências em suas leituras dos textos acadêmicos partirão dos significados constituídos pela leitura de sua história, pelos significados que constituiu até o presente, decorrendo, então, a necessidade de situações que oportunizem a reflexão sobre esses sentidos, como uma atividade de interpretação do texto da vida.

b) Formar o professor alfabetizador leitor de histórias infantis e interlocutor de atividades que delas decorrem

Ler e interpretar as histórias de outros autores, as histórias infantis e contá-las demandam outro evento de letramento: a contação de histórias. Tal situação requer a prática de leitura, a atividade de interpretação, o exercício da narrativa, além de ler a expectativa da criança, o público que ouvirá a história. Conhecer o universo da literatura infantil e interpretá-lo demanda um letramento literário, o qual exige prática. Ninguém nasce sabendo interpretar um texto literário e não é porque este segmento recebe o predicado de infantil que se torna mais fácil. Pelo contrário, há histórias infantis que requerem extrema habilidade para que se chegue ao seu requinte de interpretação, a fim de que se atinja o entendimento a que se propõe.

c) Formar o professor alfabetizador leitor da escrita infantil e, por meio dela, planejar as práticas alfabetizadoras

Ler e interpretar a escrita infantil constitui-se em mais um evento de letramento do formador do professor alfabetizador, no qual se preconiza a produção infantil como o ponto de partida para os planejamentos das atividades alfabetizadoras. A compreensão da escrita infantil requer um letramento específico do alfabetizador no que se refere às hipóteses que a criança desenvolve durante o processo de aquisição do 
sistema de escrita. As crianças elaboram ideias próprias a respeito dos sinais escritos, desde aproximadamente, os quatro anos, e possuem critérios peculiares para admitir se uma marca gráfica pode, ou não, ser lida. Ultrapassa a fase em que distingue os elementos figurativos dos não figurativos, supera os critérios de quantidade mínima de caracteres e variedade que uma palavra pode ter para se constituir como tal, adicionando letras aos seus registros e atingindo uma escrita alfabética. O papel do professor, nessa jornada, é de mediador. A criança ainda tem a etapa ortográfica a ser atingida.

d) Formar o professor alfabetizador leitor/usuário das tecnologias e, por meio destas, usá-las como suporte na alfabetização

Ler, interpretar e escrever com suporte tecnológico constitui-se em mais um evento de letramento do formador do professor alfabetizador como agente letrador. Em primeiro lugar ler e interpretar o hipertexto, informações com movimento, com mídias distintas em um mesmo plano, requer condições de leitura distintas das de um livro que se lê página a página. Usar o meio tecnológico como suporte de leitura e escrita na formação do alfabetizador constitui evento de letramento digital, e o formador é seu agente letrador. Insere o aluno em formação em práticas de leitura que estão em seu contexto e trabalha com um desafio que a sociedade informacional demanda: a seleção de informações. Não basta ler, interpretar, escrever e criar significados, pois o uso da internet demanda uma leitura que requer julgamento das informações que são oferecidas sem precedentes.

As práticas que sustentam a didática do formador do alfabetizador são apoiadas por uma práxis reflexiva, na qual teoria e prática são indissociáveis. São intencionais e estão vinculadas ao conhecimento da área de alfabetização, com a realidade das classes alfabetizadoras, com a condição dos alunos que chegam à formação universitária, com o movimento que a didática prática preconiza tendo em vista que os sujeitos que delas participam são históricos e, por meio de uma causalidade complexa, a teoria expressará a ação prática desses sujeitos. 


\section{Considerações finais}

De forma alguma a didática que aqui se apresenta pode engessar ou, sequer, servir como prescrição para a prática do formador do alfabetizador, e isso não compete traduzir-se em um limite. Conforme já mencionado, decorre das práticas produzidas, portanto constituem-se num conhecimento histórico, determinado por grupo que, certamente, em novas turmas, será revisitado pela experiência, confrontado pela realidade. Limites, sim, são encontrados e mostram-se quanto aos gêneros textuais propostos, em certa medida, com ênfase na literatura infantil. Os textos na prática alfabetizadora se ampliam em outros gêneros e, consequentemente, na formação do alfabetizador, constituindo-se em eventos de letramento distintos, e este foi um limite encontrado nas práticas produzidas, que requer atenção na produção da didática do formador do professor alfabetizador. Outra limitação refere-se à condição espaço/tempo que se traduz na universidade como agência de letramento. Em cada instituição de ensino superior há uma infraestrutura distinta como o ambiente, o material, os recursos, além da carga horária disponibilizada para a disciplina específica da alfabetização.

Porém o maior limite que se pode encontrar na didática do formador do alfabetizador está na constituição da prática dos eventos de letramento em duas dimensões: primeiro, se houver maior tendência à teorização ou ativismo, deixando a natureza da práxis reflexiva como seu eixo; em segundo lugar, não menos importante, quando não priorizar a leitura, a interpretação, a escrita e a criação de significados, ou seja, a inserção do aluno em formação em práticas sociais de leitura e escrita, considerando o letramento alfabetizador.

O letramento alfabetizador proposto nessa didática vai ao encontro do que se recomenda à formação do professor leitor. Há estudos que mostram a necessidade da formação do professor alfabetizador, como os de Chartier (2011) e Andrade (2007), na perspectiva não somente científica da área, mas também como sujeito leitor, leitor da ciência, leitor de histórias, leitor da criança, leitor da palavra, leitor 
do contexto, leitor do mundo. A leitura exige prática, e, nessa marcha, a didática do formador do alfabetizador caminha para essa direção: práticas sociais de leitura e escrita que envolvam a área da alfabetização, nas quais o aluno em formação e o formador são protagonistas do letramento alfabetizador.

Na realidade viva e mutante, este trabalho se constitui dinâmico e inacabado, sempre à busca das novas relações que a área da alfabetização impulsiona e a complexidade das práticas pedagógicas que são produzidas demandam. Portanto, é uma didática em movimento, que exige do formador, agente letrador, protagonista dos eventos de letramento nas instituições de ensino superior, constante leitura, interpretação, escrita e criação de novos significados.

E para concluir,

nas margens do mapa, encontramos sempre as fronteiras do desconhecido. O que resta fazer é interrogar os silêncios reais, por meio do diálogo do conhecimento. E, à medida que esses silêncios são penetrados, não cosemos apenas um conceito novo ao pano velho, mas vemos ser necessário reordenar todo o conjunto de conceitos. Não há nenhum altar mais oculto que seja sacrossanto de modo a obstar a indagação e a revisão (THOMPSOM, 2009, p. 229).

\section{Referências}

ABRAMOVICH, F. Literatura infantil: gostosuras e bobices. 5. ed. São Paulo: Scipione, 2006.

ANDRADE, L. T. de. Professores leitores e sua formação: transformações discursivas de conhecimentos e saberes. Belo Horizonte: Ceale; Autêntica, 2007. ANDRÉ, M. E. D. A. de. Estudo de caso em pesquisa e avaliação educacional. 3. ed. Brasília: Liber Livro, 2008. 
AZAMBUJA, J. Q. de; SOUZA, M. L. R. de. Estudo de texto como técnica de ensino. In: VEIGA, I. P. A. (Org.). Técnicas de ensino: por que não? 20. ed. Campinas: Papirus, 2009.

BARBOSA, M. L. P.; CARVALHO, R. S. de. Práticas escolares em espaços-tempos contemporâneos. In: COSTA, M. V. (Org.). A educação na cultura da mídia e do consumo. Rio de Janeiro: Lamparina, 2009.

BERNARDO, J. Marx crítico de Marx._Porto: Afrontamento, 1977.

CHARTIER, A.-M. Os futuros professores e a leitura. In: BATISTA, A. A. G.; GALVÃO, A. M. de O. (Org.). Leituras: práticas, impressos, letramentos. 3. ed. Belo Horizonte: Autêntica, 2011. p. 89-97.

CHIZZOTTI, A. Pesquisa qualitativa em ciências sociais. Petrópolis: Vozes, 2006.

COSSON, R. Letramento literário: teoria e prática. 3. ed. São Paulo: Contexto, 2009. FERREIRO, E.; TEBEROSKY, A. Psicogênese da língua escrita. Porto Alegre: Artmed, 1999.

FLICK, U. Introdução à pesquisa qualitativa. 3. ed. Porto Alegre: Artmed, 2009.

FREIRE, P. A importância do ato de ler: em três artigos que se completam. São Paulo: Cortez, 2005.

KENSKI, V. M. Educação e tecnologias: o novo ritmo da informação. 6. ed. Campinas: Papirus, 2010.

LAJOLO, M. Do mundo da leitura para a leitura do mundo. 6. ed. São Paulo: Ática, 2000.

MARTINS, P. L. O. A didática e as contradições da prática. 3. ed. Campinas: Papirus, 2009.

MORAES, R.; GALIAZZI, M. do C. Análise textual discursiva. 2. ed. Ijuí: Ed. Unijuí, 2011. 
PALFREY, J.; GASSER, U. Nascidos na era digital: entendendo a primeira geração de nativos digitais. Porto Alegre: Artmed, 2011.

SANTOS, A. F.; WINKELER, M. S. B. O desafio de formar alunos adolescentes em professores. In: CONGRESSO NACIONAL DE EDUCAÇÃO - EDUCERE, 10., SEMINÁRIO INTERNACIONAL DE REPRESENTAÇÕES SOCIAIS, SUBJETIVIDADE E EDUCAÇÃO - SIRSSE, 1., 2011, Curitiba. Anais... Curitiba: Pontifícia Universidade Católica do Paraná, 2011.

SANTOS, G. L. Formar professores para a educação mediada por tecnologias: elucidação da problemática por meio de seis investigações acadêmicas. In: SANTOS, G. L.; ANDRADE, J. B. F. de. Virtualizando a escola: migrações docentes rumo à sala de aula virtual. Brasília: Liber Livro, 2010. p. 15-28.

SILVA, M. Infoexclusão e analfabetismo digital: desafios para a educação na sociedade da informação e na cibercultura. In: FREITAS, M. T. de A. Cibercultura e formação de professores. Belo Horizonte: Autêntica, 2009.

SOARES, M. Travessia. Belo Horizonte: UFMG, 1981. Memorial apresentado à Faculdade de Educação da Universidade Federal de Minas Gerais.

STAKE, R. E. Pesquisa qualitativa: estudando como as coisas funcionam. Porto Alegre: Penso, 2011.

THOMPSON, E. P. A miséria da teoria ou um planetário de erros. Rio de Janeiro: J. Zahar, 2009.

ZACCUR, E. Aprendiz de modelo ou modelo de aprendiz? In: GARCIA, R. L. (Org.). A formação da professora alfabetizadora: reflexões sobre a prática. 4. ed. São Paulo: Cortez, 2003.

Recebido: 15/10/2010

Received: 10/15/2010

Aprovado: 20/12/2011

Approved: 12/20/2011 